\title{
PODE A DIFERENÇA INSISTIR NAS ENTRANHAS DA SUA PRÓPRIA ANIQUILAÇÃO? MULHERES, MANGUES E MOVIMENTOS
}

\author{
Rô Aragão Matias ${ }^{i}$ \\ Michele de Freitas Faria de Vasconcelos ${ }^{\text {ii }}$ \\ Sandra Raquel Santos de Oliveira ${ }^{\text {iii }}$
}

\begin{abstract}
Resumo: Esse artigo integra parte dos efeitos de um percurso de extensão e pesquisa que aproximou alunas e professoras do Departamento de Psicologia da Universidade Federal de Sergipe ao Movimento de Marisqueiras de Sergipe (MMS). Uma pesquisa que tinha como ponto de partida a intenção de acompanhar processos de invenção da vida cotidiana de mulheres marisqueiras em Sergipe, desdobrou-se na produção de um método-pensamento, uma desprendizagem que coloca em questão nossos gestos capitalísticos-empreendedores. Por meio dessa ressonância, inspirando-nos em procedimentos etnográficos e cartográficos, constituímos um território comum com as águas, o mangue, marisqueiras e pesquisadoras, a afirmar a singularidade e a singularização da vida de mulheres de povos e comunidades tradicionais.
\end{abstract}

Palavras-chave: Mulheres; Mariscagem; Corpo; Território; Resistência.

\section{PUEDE LA DIFERENCIA INSISTIR EN EL INTERIOR DE TU PROPIA ANIQUILACIÓN? MUJERES, MANGLARES Y MOVIMIENTOS}

Resumen: Este artículo integra parte de los efectos de un curso de extensión e investigación que acercó a estudiantes y docentes del Departamento de Psicología de la Universidad Federal de Sergipe al Movimiento de Mariscadoras en Sergipe (MMS). Una investigación que tuvo como punto de partida la intención de seguir los procesos de invención de la vida cotidiana de las mariscadoras de Sergipe y se desarrolló en la producción de un pensamiento metodológico que cuestiona nuestros gestos capitalistas-emprendedores. A través de esta resonancia, inspirándonos en procedimientos etnográficos y cartográficos, creamos un territorio común con aguas, manglares, mariscadores e investigadores en la dirección de afirmar la unicidad y singularización de la vida de mujeres de pueblos y comunidades tradicionales.

Palabras clave: Mujeres; Mariscos; Cuerpo; Territorio; Resistencia.

\section{Situando o território, pisando devagar ${ }^{\mathrm{iv}}$}

Tateando um modo de iniciar a feitura deste texto, salientamos três processos. Primeiramente, essa escrita, apesar de marcar a conclusão de uma etapa de pesquisa (desenrolada entre agosto de 2019 e agosto de 2020), não se dispõe necessariamente ao encerramento das discussões e atividades pré-estabelecidas no seu planejamento, mas, pelo

2021 Matias; Correio; Oliveira. Este é um artigo de acesso aberto distribuído sob os termos da Licença Creative Commons Atribuição Não Comercial-Compartilha Igual (CC BY-NC- 4.0), que permite uso, distribuição e reprodução para fins não comerciais, com a citação dos autores e da fonte original e sob a mesma licença. 


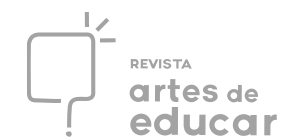

contrário, se constitui mais um passo no percurso de invenção de outros modos de saber e outras práticas ditas "psi”. Em segundo lugar, essa escrita é plural e polifônica, fruto de múltiplas trocas e ressonâncias entre um corpo de mulheres que se fez equipe de pesquisa e de extensão, entre nós e o conjunto de autoras e autores que nos baseiam, entre nós e o corpo de mulheres que se faz movimento. Assim, muito além de uma escrita individual, as palavras aqui expressas se fazem um corpo coletivo. Por último, mas não de menor importância: a contextualização feita logo a seguir não é trazida por acaso ou como mero recurso de introdução textual. Tratase de uma estratégia para que possamos localizar o saber que essa escrita pretende compor numa tentativa de "nomear onde estamos e onde não estamos" (HARAWAY, 1995, p. 21), arriscando perguntar: "com o sangue de quem foram feitos os meus olhos?" (idem, 1995, p. 25) e, assim, fazer leituras outras para, na articulação entre saberes científicos e tradicionais, pesquisar com outras mulheres, disputando modos de ver e de enunciar, por dentro da barriga do monstro que nos engoliuv ${ }^{v}$. Seguimos.

A pesquisa "Mulheres e Mariscagem: invenções de si no mundo do mangue", que oportunizou essa escrita, foi executada conjuntamente entre as equipes do grupo de pesquisa e do subprojeto de extensão intitulado "Organização e Fortalecimento Sociopolítico das Marisqueiras no Litoral de Sergipe”. Este último integra as atividades do Programa de Educação Ambiental com Comunidades Costeiras (PEAC/SE), surgido há pouco mais de dez anos enquanto exigência do licenciamento ambiental federal conduzido pelo IBAMA de áreas no litoral Sergipe/Alagoas destinadas à exploração marítima de petróleo e gás. O PEAC financiado pela Petrobrás e executado pela UFS - tem como objetivo o incentivo ao fortalecimento dos territórios de vida dos povos e comunidades tradicionais direta ou indiretamente afetados por tais atividades exploratórias. Nessa direção, utiliza aportes da Educação Ambiental Crítica para, por meio da formação popular, ampliar possibilidades de enfrentamento aos impactos socioeconômicos, com vistas a qualificar a participação dos grupos sociais afetados por meio de ações de formação política, mas também pela construção de espaços de alianças entre comunitários, entre comunidades, entre movimentos sociais. É este, portanto, o cerne do acompanhamento do Movimento de Marisqueiras de Sergipe (MMS), movimento este que busca "fortalecer coletivamente o conjunto das marisqueiras" da região de abrangência do Programa, através do "trabalho de base nas comunidades, da representação do MMS em espaços institucionais e atividades de luta, e também por meio de alianças com outros movimentos sociais" (VASCONCELOS; OLIVEIRA, 2020, p. 121), sustentadas na articulação 
[...] entre mulheres em defesa dos seus territórios de vida, contra as cercas das águas, dos territórios das comunidades; contra as cercas presentes na feitura dos corpos de mulheres de comunidades tradicionais e suas atividades políticas com vistas à produção de autonomia; contra o cerco de seus territórios corpo, ambiente, modos de vida, ali onde o social e as subjetividades se co-engendram (idem, 2020, p. 121).

É para esta atividade de acompanhamento que se voltam as extensionistas do subprojeto de Organização e Fortalecimento Sociopolítico das Marisqueiras, e é também a partir dela que a reestruturação do PEAC feita pelo IBAMA passou a considerar a execução de projetos de pesquisa que fundamentem a delimitação de áreas e grupos sociais que de fato são pertinentes à mitigação, de modo a constituí-los enquanto sujeitos de um projeto educativo-crítico. É aí, no emaranhado dessa rede, que a equipe de pesquisadoras da qual fazemos parte - em articulação com outras estudantes da graduação e da pós-graduação, professoras da UFS e outras universidades, técnicas do PEAC e marisqueiras - aposta num fazer pesquisa com um movimento social, o MMS, ainda em processo de constituição, cartografando suas derivas. Dentre os objetivos delineados como parte desse fazer pesquisa estão o acompanhamento de processos de invenção da vida cotidiana de mulheres marisqueiras, conhecendo os modos de vida dessas mulheres em Sergipe; assim como o mapeamento das táticas e estratégias de (re)existência ao capital e ao patriarcado que incidem nas relações cotidianas, domiciliares, com seus companheiros, nas colônias de pescadores, nas cercas e barragens dos grandes empreendimentos, na carcinicultura ${ }^{\mathrm{vi}}$, em si mesmas.

\section{Sobre um modo de pesquisar, com}

Os métodos de uma ciência positivista - com seus percursos hierarquizantes, legitimadores das distinções que se fazem entre sujeito e objeto, pesquisadoras e pesquisadas, acadêmicas e marisqueiras, e seus olhares advindos do alto dos pedestais sacralizados em suas indisputáveis tautologias -, não atendem às nossas investidas no acompanhamento dos processos de invenção da vida cotidiana de mulheres marisqueiras. Isso porque a objetividade científica, tal qual disposta pelo corolário científico moderno, tanto em seu "sobrevoo do objeto", quanto em sua "pressuposição de neutralidade e não implicação com o conhecimento produzido" (PASSOS; KASTRUP, 2013, p. 395), acaba por falar "sobre a realidade e não com ela" (KASTRUP; PASSOS, 2013, p. 272). 


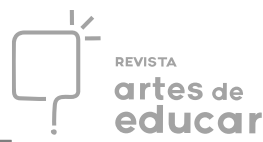

Assim, articuladas com Donna Haraway (1995), pretendemos multiplicar os sentidos para termos tão "caros" para a ciência: objetividade e rigor. Não nos dispomos à construção de um conhecimento como representação da realidade, como não nos propomos a fazer desse conhecimento uma verdade irrefutável, universal e homogeneizante, um ideal regulador ou um projeto de uniformização de modos de vida e modos de produzir conhecimento. Pelo contrário: buscamos muito mais nos arriscar pelas trilhas enlameadas que sobem à jusante das margens do rio do que seguir pelas estradas pavimentadas que descem em direção à sua foz. No limite, não é apenas uma escolha sobre por onde navegar, mas sobre quais mundos escolhemos percorrer e quais nos dispomos a produzir. A aposta dessa pesquisa se faz na corrosão das cercas e das posturas verticalmente assépticas que separam o mangue e a universidade, na tentativa de compor planos de análise coletiva lá, aqui e acolá, por meio da criação de um território de vida e de pesquisa comuns, criando um comum entre heterogêneos. Esse é o nosso rigor: acessar o plano da experiência por meio do protagonismo de todas as pessoas envolvidas na pesquisa. Nós, as águas. Nós, o mangue. Nós, corpos feitos como de mulheres. Nós, as marisqueiras. Nós, as pesquisadoras. Nós, corpo coletivo.

Nesse sentido, não nos conduzimos por e para um mapeamento descorporificado das formas visíveis, mas por meio de investidas parciais e localizadas que buscaram - e buscam acompanhar as múltiplas linhas de força que atravessam e constituem a visibilidade das formas. Se nos dispomos diante da tentativa de acompanhar o delineamento das linhas de fuga que mais definem as formações sociais do que suas próprias contradições (DELEUZE, 1992), o fazemos por uma espécie de princípio metodológico que "orienta para detectar forças tendenciais, direções, movimentos, que escapam aos planos das formas", já que "não se pode abordar um campo movente senão com uma estratégia que seja em conformidade com sua natureza" (KASTRUP, 2000, p. 07-08). Seguimos, portanto, muito menos por receitas e manuais finalizados, muito mais por pistas inacabadas de um fazer cartográfico, mas também etnográfico, que miram nas processualidades que atravessam a invenção da vida cotidiana das mulheres no mundo do mangue, com ênfase nas táticas e estratégias de reinventar existências por elas protagonizadas.

Para isso, utilizamo-nos dos instrumentos metodológicos de diários de campo, além da produção de relatorias e da gravação de áudios e suas transcrições em rodas de conversa e momentos de formação política com as marisqueiras, de modo a fazer a escrita e a escuta comporem com a fala "zonas de indiscernibilidade" (KASTRUP; PASSOS, 2013, p. 266), próprias de um comum no qual se partilha e se pertence no seio da heterogeneidade de múltiplas 
singularidades em comunicação, na convivência das múltiplas belezas de nossas esquisitices ${ }^{\mathrm{vii}}$. É nessa região, onde nada claramente se distingue e onde nada de ninguém é exclusivo, que pululam as múltiplas linhas rizomáticas que, como as raízes acêntricas do manguezal, constituem as redes de articulação e composição nas quais estamos todas implicadas. Nessa região, tão pré-individual quanto coletiva, diluem-se os limites que possam existir entre as mulheres da academia e aquelas que habitam as comunidades tradicionais, mas também entre nós e nós mesmas, entre elas e elas mesmas.

E é essa região - onde se desestabiliza a hierarquização dos diferentes, onde lugar de fala não vem de tais hierarquizações nem tampouco de armaduras identitárias (nem em nome do outro, nem em nome do que sou e devo seguir sendo), e onde se faz tremer a constituição de um corpo homogêneo - que nos convoca a habitar a instabilidade dos limites desafiadores e não definitivos "entre o que comuna e o que difere; entre o que conecta os diferentes sujeitos e objetos implicados no processo de pesquisa e o que, nessa conexão, tensiona; entre o que regula o conhecimento e o que o mergulha na experiência" (KASTRUP; PASSOS, 2013, p. 267). É aí que nos dispomos a levar adiante, com essas mulheres e ao lado delas, um trabalho coletivo de invenção do conhecimento. É também aí, sobretudo, que nos propomos todas, intercessoras umas das outras, ao trabalho coletivo de transformação da vida.

No entanto, se, por um lado, não nos exprimimos sem nossas intercessoras tal qual elas não se exprimiriam sem a nossa interseção, no sentido de que "sempre se trabalha em várias, mesmo quando isso não se vê" (DELEUZE, 1992, p. 156), por outro, não nos atrevemos a pensar a afirmativa deleuziana como se estivéssemos reproduzindo os milagres messiânicos de conceder o dom da fala ao surdo-mudo da Decápole ou de expulsar o demônio da mudez. Não tomemos a fala como o fogo dos deuses, muito menos a nós como o bondoso Prometeu. Não é sobre dar a voz, ou melhor, não deveria ser. Que nos arrisquemos a dizer que voz nenhuma foi tomada; os ouvidos é que foram adestrados numa espécie de surdez seletiva, tal qual os olhos induzidos a perder a capacidade de enxergar à sombra.

Todavia, também não é, ou não deveria ser, meramente sobre ceder ouvidos; tampouco sobre dispor lentes que ajustem as coisas ao ponto confortável que pedem os nossos olhos. É mais sobre acostumar os ouvidos a escutar o que não foi dito, a se demorar no que ainda não possui significado ou saiu sem se fazer audível, a intuir o que se diz de maneira indiscernível por debaixo do ruído. Sobre ensinar aos olhos, vestidos ou não de lentes, a lidar com as coisas em suas próprias miudezas sem necessariamente trazê-las à luz, mas ali, nas penumbras onde elas se localizam. Em outras palavras, não nos permitamos atribuir a nós a gênese de qualquer 
movimento, muito menos a tarefa de localizar qualquer origem que seja. Deleuze (1992) bem nos disse que não mais se define a origem dos movimentos enquanto um ponto de partida, originário e temporal, mas por uma certa maneira de colocação em órbita. Menos impulsos unilaterais, mais mútuas ressonâncias.

O que o pensador francês disse encarna-se no cheiro do mangue, cheiro do corpo feito da lama de Nanã, no qual soprou-se a vida. Se o movimento algum dia começou, podemos narrá-lo ao sabor, som e luzes das velhas tradições, pois se há verdade, ela se dá na produção da existência, não nas reedificações caducas de palavras, frases e ideias ditas científicas. Retomando a pergunta feita por Donna Haraway (1995) trazida anteriormente: com que sangue foram feitos esses nossos olhos de cientistas? Desde a cidade de Aracaju, em que as plantações de concreto do famoso bairro Jardins aterraram e substituíram uma área gigantesca de manguezal, berço de tantas vidas, de oxigênio e de modos de vida de mulheres encantadoras de mariscos, preferimos olhar as reminiscências do mangue que resiste ou as resistências do mangue que remanesce, avistar ali a mistura da vida acontecendo, começando de novo, mesmo num momento em que esse ecossistema de vida e pensamento está sendo aniquilado; em que, em nome do progresso e desenvolvimento, a voz da ciência autoriza que mais e mais áreas de manguezais deem lugar a empreendimentos capitalísticos. Com nossas pesquisas, não se trata, pois, ou pelo menos não só, de observar e descrever uma realidade dada; trata-se de politizar o olhar, uma vez que modos de olhar não descobrem, mas produzem modos de viver. A questão, então, nos parece ser: que modos de viver queremos afirmar com nossas pesquisas? Ou ainda: que gestos, práticas, modos de viver queremos fazer vacilar? Que gestos, práticas, modos de viver queremos compor?

Por isso, que possamos nos permitir escrever líquido ou gasoso na tentativa de abandonar a solidez e a geometria das percepções e opiniões ordinárias. "Nada de abandonar a terra. Mas tornar-se tanto mais terrestre quanto se inventa leis do líquido e do gasoso de que a terra depende" (DELEUZE, 1992, p. 167). Que possamos soprar a terra do corpo para tremer as territorializações inscritas na pele, cuja superficialidade é desse corpo o mais profundo. Que possamos nos inserir entre a mutabilidade das ondas pré-existentes nas marés e o revirar da lama que as correntes da água produzem no leito dos rios, se fazer água e lama revirada, em vez de petrificar a verdade sobre supostos modos de funcionamento, a fim de que estes continuem a empreender. 


\section{Rumo ao progresso e desenvolvimento: ecocídio, genocídio e etnocídio}

Num contexto de medidas mitigatórias e compensatórias, nós, extensionistas e pesquisadoras, nos propomos ao acompanhamento das mulheres de quatorze comunidades tradicionais, apontadas a partir do Diagnóstico de Vulnerabilidade das Marisqueiras realizado pelo PEAC entre 2013 e 2014, que considerou prioritárias as áreas com maior possibilidade de exposição aos impactos socioeconômicos das atividades exploratórias exercidas pela Petrobrás. Com efeito, dizer que esta pesquisa se gesta na linha tênue entre a iminente concessão e a custosa reparação de territórios e modos de vida é insistir na exposição do tamanho do monstro que nos engoliu paralela à necessária constatação de que nos localizamos em seu trato digestivo (pedimos licença a Donna Haraway para navegar com sua metáfora de maneira, talvez, indelicada): assumir o PEAC como as entranhas deste monstro é entendê-lo enquanto expressão institucionalizada do funcionamento de uma lógica predatória, ainda que, em sua contradição intrínseca, o programa seja, ao mesmo tempo, ferramenta ímpar no amaciamento dos impactos desta predação.

Falar desde a barriga de um processo mitigatório é, portanto, falar do necessário embate diante do qual nos colocamos: de um lado, os movimentos peristálticos de uma degradação territorial; do outro, a potência indigesta de uma luta constante pela manutenção da saúde desses - ou pela produção de saúde nesses - desses territórios. E, por territórios, não entendamos apenas espaços geográficos antropicamente delimitados e suas ditas riquezas naturais; façamos o movimento de perceber, também, os espaços sociais e afetivos que os constituem e, por isso, os atravessam, ou que os atravessam e, por isso, os constituem. Falamos, então, não apenas de comunidades tradicionais e suas geografias, mas, também, de populações que residem nessas comunidades e, ainda, de mulheres enquanto sujeitos - individuais e coletivos - que constituem essas populações. Não obstante, ainda que entendamos tais territórios enquanto instâncias distintas, nos esforcemos para não operar sobre eles relações de separabilidade e hierarquização: tratam-se de três registros territoriais ou, para usar as palavras de Félix Guattari (2001), três ecologias intrinsecamente relacionadas entre si e necessariamente dependentes umas das outras. Dito desse modo, parece ficar evidente que entendemos saúde aqui como efeito de condições coletivas de existência e como afirmação de modos de vida singulares e em singularização. “Ei, [...] insistimos aqui!” (VASCONCELOS; OLIVEIRA, 2020, p. 123).

É nesse sentido que o autor supracitado se empenha desde os momentos iniciais de seu livro “As Três Ecologias” na elaboração de um panorama, ou melhor, de um diagnóstico sobre 


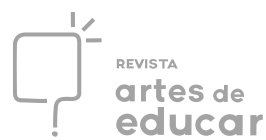

os constantes e perpendiculares processos de degradação ecológica que estão em curso na atualidade: a ambiental, a social e a mental. E o faz não para oferecer um documento último na análise das relações até então produzidas e sustentadas, muito menos para congelar marcos temporais no percurso da história, mas para suscitar aberturas em direção à reinvenção da "produção de existência humana em novos contextos históricos" (GUATTARI, 2001, p. 15). Ainda de acordo com o pensador francês, "o que está em questão é a maneira de viver daqui em diante sobre esse planeta, no contexto da aceleração das mutações técnico-científicas e do considerável crescimento demográfico" (idem, 2001, p. 08). Daí, nos intima a dissolver miopias diante da factual impossibilidade de continuarmos sustentando um modo de produção econômica e, sobretudo, subjetiva pautado na subsunção compulsória e irresponsável de toda e qualquer natureza e humanidade à lógica do lucro, operada pelo que o autor convencionou chamar de Capitalismo Mundial Integrado.

Pierre Clastres (2004, p. 62), em sua “Arqueologia da Violência”, referiu-se a este modo de operar enquanto "sistema de produção para o qual nada é impossivel, exceto não ser para si mesmo seu próprio fim". Em outras palavras: os processos de degradação ecológica são, simultaneamente, raízes e esporos do modus operandi capitalista. Se, por um lado, são os substratos que o fixa e o sustenta, por outro, constituem suas unidades de reprodução numa marcha cíclica e irrefreável cuja substituição de modos de ser e viver alheios aos seus interesses "se cumprirá até o fim, só acabará quando não houver absolutamente mais nada para mudar" (CLASTRES, 2004, p. 63). É nesse sentido que o autor afirma, ainda, que

[...] a sociedade industrial, a mais formidável máquina de produzir, é por isso mesmo a mais terrível máquina de destruir. Raças, sociedades, indivíduos; espaço, natureza, mares, florestas, subsolo: tudo é útil, tudo deve ser utilizado, tudo deve ser produtivo; de uma produtividade levada a seu regime máximo de intensidade (idem, 2004, p. 62).

Mangues, marés, mariscos, mulheres, modos de vida: tudo é útil, tudo deve ser utilizado, tudo deve ser produtivo. Decerto, pareceria equivocado parearmos análises de momentos distintos desse modelo de produção: enquanto Guattari discorre seu pensamento diante de um capitalismo que se faz cada vez mais financeiro e internacional, Clastres o analisa através de sua atividade no gérmen de um processo de internacionalização. Por isso mesmo, pareceria anacrônico nos apoiarmos na crítica do funcionamento de um capitalismo industrial; ora, há muito a empresa substituiu a fábrica e o corpo massificado de proletários deu lugar a maratonas percorridas por empreendedores individuais que nunca se aproximarão da linha de chegada 


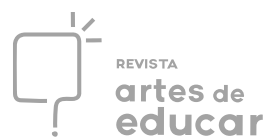

(ROSE, 2011). No entanto, o fazemos por entendermos que desde o seu surgimento, apesar das variadas folhagens, este modelo de produção permanece sendo a mesma erva daninha cujas raízes penetram em todos os tecidos e sugam incansavelmente toda a natureza de nutrientes que possam ser transformados em capital. Não nos prestemos, inclusive, à ingenuidade de desconsiderar que as noções de desenvolvimento e progresso amparadas no sistema-mundo ${ }^{\text {viii }}$ capitalista e que, vulgarmente, são entendidas enquanto seus sinônimos, povoam nosso imaginário desde a expansão marítima comercial e os consequentes processos de colonização ocorridos entre o final do século XV e o início do século XVI.

Said Bouamama ${ }^{\mathrm{ix}}$, por exemplo, e outros pensadores dos processos de dominação nos ajudam a entender o fato de que capitalismo e colonialismo são as faces de uma mesma moeda, construída com base na espoliação de territórios e no sequestro, racialização, escravização e assassinato de corpos ameríndios e africanos que, pelo menos aqui, onde convencionou-se chamar de América Latina, perdura desde 1492. Não nos furtemos, então, ao movimento de considerar que, além das léguas temporais e da capacidade predatória dos aparelhos estatais, não há muita distância entre a extração colonial de pau-brasil e os recordes de desmatamento durante os últimos dois anos. Ou, ainda, entre o despejo de mercúrio nos rios brasileiros durante o auge da corrida do ouro no antepenúltimo século e o que acontece agora mesmo - aliás, digase de passagem, as atividades de mineração são as causadoras de dois dos maiores desastres ambientais da história do país: o rompimento das barragens de Mariana e Brumadinho, em 2015 e 2019, respectivamente. Por conseguinte, não distam entre si os fins das velhas e novas práticas de encarceramento e genocídio das populações negras, apesar das transformações nos meios pelas quais elas são executadas, afinal todo camburão tem um pouco de navio negreirox; muito menos as velhas e novas práticas de catequização e genocídio das populações indígenas, pois os jesuítas de ontem são os ex-missionários nos altos cargos da FUNAI de hoje.

Solicitamos, pois, a paciência de leitoras para assumir o risco da ousadia em prosseguir com analogias que talvez sejam impalatáveis: alguns séculos depois, naus e caravelas deram lugar às multinacionais e as doenças trazidas pela migração dos colonizadores deram lugar às intoxicações por efluentes nocivos; os escravizados que antes eram responsabilizados pelas colheitas, cozinhas e crianças tornaram-se entregadores de aplicativos, empregadas domésticas e babás. Milícias atualizam bandeirantes ${ }^{\mathrm{xi}}$; penitenciárias atualizam senzalas; casas de recuperação, carvoarias e setores da indústria da moda atualizam trabalhos escravos. A mão cadaverizante que, nos tempos passados, conduziu territórios e populações inteiras à agonia vestiu-se de luvas brilhantemente tecnológicas, aparatou-se de anéis automatizados e equipou- 
se de instrumentos informatizados para prosseguir com a mesma sinfonia de degradação ambiental, social e mental. Que não vos pareça um displicente exagero ou a tentativa desesperada de reforçar o decalque das linhas trágicas da história... O fazemos no sentido de reafirmar que é imprescindível reconhecer as capciosas habilidades de mutação do monstro com o qual nos propomos lidar, inclusive para traçar estratégias efetivas de combate.

Nesse sentido, quase um ano depois do maior acidente ambiental em extensão já registrado no país, a saber, o derramamento de toneladas de petróleo cru em toda a costa litorânea do nordeste - e parte do sudeste - brasileiro, diante do qual não houve acionamento do Plano Nacional de Contingência para Incidentes de Poluição por Óleo (PNC) e cuja limpeza foi feita majoritariamente pelas populações tradicionais e urbanas das áreas costeiras afetadas, “como compreender a demora, as não respostas, nesse caso, como mera passividade de deixar morrer? Como entender de forma desconectada a agonia de não poder mariscar e perder a principal fonte de renda e alimentação e a destruição dos próprios territórios existenciais?" (VASCONCELOS; OLIVEIRA, 2020, p. 122). Se assumimos, anteriormente, que os três registros ecológicos mencionados constituem-se ao passo em que se atravessam, não pensemos que extrativismos e predações os atinjam separadamente. Estamos falando, portanto, de uma cadeia destrutiva que atinge biomas inteiros, seus animais e suas vegetações, bem como formações socioculturais que ali se sustentam e populações humanas que dali dependem, multiplicidades subjetivas que ali se produzem. Ecocídio ${ }^{\text {xii }}$, genocídio e etnocídio ${ }^{\text {xii }}$ simultaneamente operados pelo mesmo monstro de múltiplas faces.

Diante do exposto, reforcemos o caráter muito mais criminoso e muito menos acidental $^{\text {xiv }}$ do evento mencionado acima e o entendamos enquanto a expressão pontual e catastrófica de uma lógica de mortificação que há muito tempo vem se fazendo diluída nos cotidianos, atravessando e constituindo as práticas quase que sem ser percebida, e, quando percebida, sendo desavergonhadamente justificada. E dessa forma acontece porque, para além das engrenagens que fazem funcionar um modelo de produção econômica, estão a rodar outras - e ainda assim, as mesmas - que permitem funcionar um modelo de produção subjetiva: "produção do desejo; (...) produção de formas de viver, de sentir, de conhecer etc." (KASTRUP, 2000, p. 06-07). Constituímo-nos, pois, diante das investidas daquilo que passamos a entender por progresso no seio de um "mito da modernidade" (DUSSEL, 1993, p. 77), nas areias movediças de uma dupla consciência (GONÇALVES, 2016): constantemente cedendo, ao passo em que constantemente resistindo, à produção de um modo de vida racional "sobre o qual se instaurou o desenvolvimento da sociedade nos últimos séculos" de maneira 
pareada "à dominação (da natureza e do homem sobre o homem, incluindo a do indivíduo sobre si mesmo) e à reificação da sociedade e da própria subjetividade” (JUNIOR, 2018, p. 52).

Estamos falando, portanto, da produção de si, da produção dos sujeitos e de seus mundos correlatos. Ou melhor, da disputa entre diferentes modalidades dessa produção; mais precisamente, da progressiva derrota expressa pela subsunção de multiplicidades subjetivas à lógica do empreendedorismo pois, como bem nos lembrou Ailton Krenak (2019, p. 15), "se existe uma ânsia por consumir a natureza, existe também uma por consumir subjetividades as nossas subjetividades". E é justamente a capacidade desse poder-sujeição emergir de baixo, dos próprios sujeitos, de forma democrática e horizontal, articulando-se à heterogeneidade e singularidades, que torna o monstro etnocida tão difícil de combater. Significa dizer, em outras palavras, que o indígena pode se tornar um cidadão brasileiro e a marisqueira uma empreendedora da pesca artesanal, de modo a fazer funcionar uma identificação - lê-se, tornar idêntico - ao modelo imposto pela "possibilidade de melhoramentos". Lidamos, então, não apenas com a degradação das formas físicas que preenchem o mundo - o tronco da árvore, o leito do rio, as raízes do mangue, as paredes do corpo -, mas sobretudo com "a destruição sistemática dos modos de vida e pensamento de povos diferentes daqueles que empreendem sua destruição" (CLASTRES, 2004, p. 56).

A descrição biopolítica de uma racionalidade governamental amparada na "mera passividade de deixar morrer" não mais parece ser suficiente no fiar das análises que carecemos compor. O "fazer viver, deixar morrer" pautado nas práticas "da incitação, do reforço e da vigilância" (PELBART, 2013, p. 26) cruza-se, de maneira complexa e nefasta, ao "fazer morrer, deixar viver" conduzido pelo poder de um estado neoliberal soberano que opera por "um mecanismo de subtração, ou extorsão, seja da riqueza, do trabalho, do corpo, do sangue" (idem, p. 25), do peixe, do marisco, da mulher e do mangue, criando sobreviventes, produzindo sobrevida. Trata-se, portanto, segundo Giorgio Agamben (1999, p. 205 apud PELBART, 2013, p. 26),

[...] de separar a cada vez a vida orgânica da vida animal, o não humano do humano. [...] A ambição suprema do biopoder é realizar a separação absoluta do vivente e do falante, [...] fazer sobreviver, produzir um estado de sobrevida biológica, reduzir o homem a essa dimensão residual, não humana, vida vegetativa.

Se a produção de sobrevida "inclui plenamente a democracia ocidental, a sociedade de consumo, o hedonismo de massa, a medicalização da existência" (PELBART, 2013, p. 27), o 


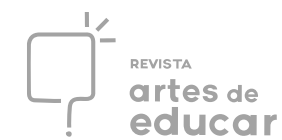

faz necessariamente enquanto parte do processo de produção de um regime econômico e subjetivo que aprofunda suas lógicas necropolíticas de desumanização e industrialização da morte quando se percebe em crise, na tentativa de "integrar a racionalidade instrumental com a racionalidade produtiva e administrativa do mundo ocidental moderno" (MBEMBE, 2016, p. 129). O neoliberalismo e seus modos científicos de governo são, sobretudo, exercícios da destruição subjetiva daqueles que não atendem ou sobraram nos processos de constituição de subjetividades empreendedoras. Aqui, mais uma vez, a pergunta de Haraway (1995) segue a marteladas: com que sangue foram feitos nossos olhos, de cientistas?

À vista disso, nos atrevamos a ratificar: matar é tanto poluir o rio quanto derramar o sangue; é tanto não reconhecer o trabalho da marisqueira quanto profanar o cheiro do mangue ao mesmo tempo em que a faz pensar que o cheiro do mangue não é, e não mais pode ser, o cheiro do teu corpo. Mas: "e que cheiro tem esse corpo agora? Que outros tipos de mortes serão inventados para que a engrenagem desse modelo predatório continue funcionando?" (VASCONCELOS; OLIVEIRA, 2020, p. 122). Diante dessa produção massiva de subjetividades empreendedoras operada perpendicular e intrinsecamente às investidas necropolíticas de uma soberania neoliberal mundialmente integrada, cujos impactos na natureza e em seus territórios, inclusive, existenciais, parecem ser tão irreversíveis quanto o tempo e a história, como desenhar linhas de frente? De lado? De trás? Ou, ainda, diante das batalhas cotidianas de uma guerra declarada "à nossa revelia, uma guerra estruturante da paz desse mundo e feita contra nós" (MOMBAÇA, 2016, p. 10), como fabular linhas de fuga?

\section{Pequenos gestos de uma pesquisa que se faz movimento na tentativa de barrar a alavanca do progresso suicida ${ }^{x v}$}

Uma pesquisa surgida nas entranhas de um processo mitigatório efetivado por um Programa de Educação Ambiental estaria certamente atravessada pelas linhas que constituem uma dada perspectiva de educação. Como mencionado nos momentos iniciais desta escrita, o PEAC, em sua proposta de fortalecimento de territórios e populações potencialmente afetadas pelas atividades de exploração nas zonas costeiras sergipanas, utiliza aportes da chamada Educação Ambiental Crítica. Esta perspectiva de educação ambiental parte do escopo das pedagogias emancipatórias que veem a educação como "elemento de transformação social [...], inspirada no fortalecimento dos sujeitos, no exercício da cidadania, para a superação das 
formas de dominação capitalistas" (LOUREIRO, 2004, p. 66-67). Assim, propõe-se a questionar tanto os pressupostos epistemológicos quanto os percursos metodológicos de uma perspectiva educativa - diga-se de passagem, ainda hoje hegemônica nos dispositivos midiáticos e pedagógicos - pautada na "resolução de problemas ambientais por meio da transmissão de conhecimentos ecológicos e da sensibilização" (LOUREIRO, 2012, p. 82) dos indivíduos que atrelam as soluções da 'questão ambiental' às mudanças em atitudes e valores comportamentais.

Que seja válido enfatizar tais assimetrias entre as perspectivas de educação ambiental mencionadas pois, no final das contas, o que está em jogo são distintas maneiras de invenção de uma ética e de uma estética da produção da existência. A nós, interessa ensaiar uma educação menor, atenta às miudezas, às mutações que acontecem no chão dos territórios quando ali nos encontramos. Assim, muito mais do que buscar uma delimitação conceitual do que se entende por educação ambiental, o que nos interessa é tatear o que ela nos possibilita fazer; muito menos saber o que ela é, muito mais entender quais agenciamentos a produzem e quais, por meio de suas diversas e distintas perspectivas, podemos produzir.

Dessa maneira, delineia-se uma aposta: reconstruir as engrenagens sociais a partir de "uma articulação ético-política entre os três registros ecológicos" que se dê "menos por reformas de cúpula, leis, decretos, programas burocráticos do que pela promoção de práticas inovadoras, pela disseminação de experiências alternativas" (GUATTARI, 2001, p. 44), inclusive educacionais. E, ainda segundo o autor, intervenções comunicacionais, por si só, não seriam capazes de operar essa reconstrução; é preciso, portanto, ensaiar mutações existenciais, as quais dizem respeito à produção da subjetividade. Nesse sentido, que nos atentemos à necessidade de "criar um desvio da fala. Criar foi sempre coisa distinta de comunicar. $O$ importante talvez venha a ser criar vacúolos de não-comunicação, interruptores para escapar ao controle" (DELEUZE, 1992, p. 217).

Suely Rolnik (1995) afirma que tal tarefa de reconstrução pode se dar a partir de uma ecologia da subjetividade que busque proceder à problematização das fronteiras visíveis e supostamente estáticas entre o dentro e o fora de cidadãos atomizados, identificados, unidades juridicamente circunscritas, compostas por uma penca de direitos e deveres legalmente garantidos; e, não obstante, à reinvenção dos aparelhos democráticos. Daí, apesar dos objetivos fundamentais firmados pela Política Nacional de Educação Ambiental (PNEA) entenderem " $a$ defesa da qualidade ambiental como um valor inseparável do exercício da cidadania" (OLIVEIRA et al., 2015, p. 05), que não nos seja suficiente "a estruturação de processos 
participativos que possam favorecer e garantir" (ibidem) esse exercício, pois a mera elevação dos sujeitos à categoria de cidadãos (plenos) de direitos acaba por tangenciar o entendimento de que uma saída para os quadros de degradação ecológica só será possível a partir da reinvenção dos próprios dispositivos institucionais que estabelecem umas ou outras noções de cidadania: os jurídicos, os administrativos, os penais etc.

Em outras palavras, nos atrevamos a dizer: muito menos que uma busca pela democracia, muito mais promover sua reinvenção. Nossa tarefa é, pois, a de experimentar; fabular maneiras outras de constituir modos de existência; inventar novas "possibilidades de vida que também dizem respeito à morte: não a existência como sujeito, mas como obra de arte" (DELEUZE, 1992, p. 116). No horizonte, uma paixão se anuncia: buscar formas de produção de subjetividades que borrem as noções de individualidade moderna, que extrapolem as identidades a partir dos fluxos e linhas que compõem a dimensão invisível da alteridade e da coexistência entre os corpos, nas quais "se produzem turbulências e transformações irreversíveis" (ROLNIK, 1995, p. 03). Enfim: nossa tarefa é a de afirmar nossa potência criadora diante da irreversibilidade dos processos vitais; de pensar a fuga por meio da nossa própria impossibilidade de fugir.

A essa altura, talvez, ainda ecoem alguns questionamentos: como encontrar formas de insubordinação numa sociedade da aniquilação da diferença em larga escala, da produção de refugos humanos ${ }^{\mathrm{xvi}}$, de pessoas dispensáveis, de vidas infames ${ }^{\mathrm{xvii}}$ ? Como nos movimentar com mulheres tendo essas perguntas como nortes encorajando-nos a forjar corpos e subjetividades outras? Se, por um lado, tanto nos questionamos sobre a capacidade de mutação e assimilação do monstro com o qual lidamos, por outro, e por isso mesmo, nos dispomos à necessária tarefa de inventar múltiplas táticas de combate. Nesse sentido, prosseguir com o exercício constante de propor questionamentos é menos pela ambição de nos saciarmos com respostas, e mais pela tentativa de ensaiarmos saídas possíveis; é entender, tal qual Gilberto Gil diria, que resolver ter os problemas é tê-los, ao passo que resolver ignorá-los também é tê-los, e acabar insistindo na resolução de ambos os lados desta equação ${ }^{\text {xviii }}$, mesmo que os sistemas multipolares suscitados pelos conflitos com os quais lidamos não sejam compatíveis a proposições tão maniqueístas assim (GUATTARI, 2001). Pois, inclusive, se foram várias as entradas que nos trouxeram por estes percursos-modos de ser e viver, que sejam várias as saídas que possam nos conduzir a outros rumos.

Daí, portanto, que não nos atrevamos a acreditar num suposto equilíbrio linear e reversível do tempo e da história, ou ainda, do tempo da história, que elegeu uma modernidade 


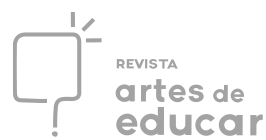

ocidental eterna enquanto ponto de chegada e que acredita ser a racionalidade instrumental o único meio possível de conduzir-nos em direção ao "progresso", destino natural de todos os povos e territórios. O que passamos a entender enquanto progresso no seio dessa modernidade ocidental é uma via expressa de mão única cujo único objetivo é o de prosseguir, independentemente das ecologias que para isso precisem perecer. Seu rolo compressor, que firma o tapete asfáltico, e seus postes ultra iluminados anunciam sua passada civilizatória, e no mesmo gesto encobrem e ofuscam a crueza de sua barbárie nos processos de construção de seus aparelhos supostamente democráticos. É tanto a marcha para o oeste, quanto a rodovia transamazônica. Tanto a corrida espacial, quanto a invenção da bomba atômica. É por esta via expressa que há muito estamos caminhando e, para além disso, desejando caminhar, porque assim fomos formadas a fazer; e é na tentativa de repensá-la justamente na vertigem de seu fluxo que nos propomos a tarefa de brecá-lo: muito menos sobre parar de andar ou voltar atrás por cima dos próprios passos, nossa tarefa parece ser descobrir maneiras outras de caminhar, por trilhas político-afetivas que nos apontem outras direções.

Entendamos, assim, nossas intercessões com a perspectiva da Educação Ambiental Crítica. Por meio dela, por exemplo, Paulo Freire (1996, p. 31) nos põe a pensar que "uma das bonitezas de nossa maneira de estar no mundo, como seres históricos, é a capacidade de, intervindo no mundo, conhecer o mundo". E intervir no mundo passa, necessariamente, por disputar a construção das narrativas que o compõem, desde ali, tanto de onde se fala quanto de onde se vive, porque a leitura do mundo é anterior à leitura da palavra; por trair os mapas linguísticos que nos aprisionam ${ }^{\mathrm{xix}}$. Justamente por isso, nos poupemos da mera transmissão do conhecimento - que, por si só, pressupõe hierarquias: as que se fazem entre aqueles (no masculino mesmo) que supostamente sabem e, por isso, ensinam, pesquisam e formam e aqueles aos quais julgam nada saber e, por isso, são ensinados, pesquisados e formados; as que se fazem entre as peles; as que se fazem entre os bolsos e suas monetárias quantias; entre as gentes, entre os gêneros, entre as geografias -, tida como praxe das viciadas estratégias educacionais em seus diferentes níveis, inclusive o universitário. Nos poupemos, portanto, da prática de uma "educação bancária" que nos ponha, adaptadas, a endossar a "ideologia fatalista, imobilizante, que (...) insiste em convencer-nos de que nada podemos contra a realidade social" (FREIRE, 1996, p. 21).

Que possamos, então, teimar em seguir nessa direção: a cada reunião de assessoria junto ao Movimento de Mulheres Marisqueiras e a cada oficina feita nas comunidades - recebendo universitárias e companheiras de outras localidades - ou na universidade, organizadas a partir 


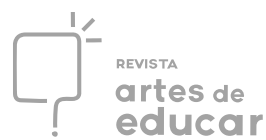

de um planejamento cuidadoso, especialmente nos procedimentos metodológicos; a cada pauta e processo formativo pensados com a cautela e o rigor de ativar um pensamento coletivo, de desenvolver análises coletivas do que se passa, de acessar o plano movente das forças. E a partir daí, ensaiar a forjadura do caminho no vórtice do encontro, de modo que o chão seja feito a cada passo e que, juntas, aprendamos, cada dia um pouco, a nos desfazer e refazer mulheres em processo de liberação. Pois que, tanto nos "seria absurdo querer voltar atrás para tentar reconstituir as antigas maneiras de viver" (GUATTARI, 2001, p. 24), quanto aceitar prontamente a continuação de um empreendimento econômico e subjetivo que valora a concorrência em detrimento de nossas multiplicidades.

Se a "nossa previsão de futuro [...] não se relaciona mais a um universo já dado, mas a um mundo de possibilidades" (PRIGOGINE, 2001, p. 78), que uma delas, então, possa ser a de atrasar a locomotiva desembestada que nos leva pelos trilhos do progresso, ainda mais porque o fim da raça humana e das demais formas de vida do planeta "é agora, pela primeira vez desde o começo da humanidade, nada além de uma simples possibilidade científica", como bem nos disse Gabriel García Márquez em seu discurso na ocasião de recebimento do Prêmio Nobel de Literatura. Tal qual nos lembrou Paulo Arantes numa conferência realizada no auditório da Associação de Docentes da Universidade Federal de Sergipe ${ }^{\mathrm{xx}}$, o relógio do fim do mundo está em minutos para a meia-noite, e o tardar da hora nos aproxima da destruição completa por uma guerra nuclear; do badalar do sino derradeiro, que de uma vez por todas impedirá as manhãs de serem tecidas pelos galos e os galos de tecerem suas manhãs. Mais uma vez: não há lugares a voltar, mas há aqueles aos quais não queremos ir. Se o tempo ou é invenção ou é nada ${ }^{x x i}$, que possamos inventá-lo, desinventá-lo ou reinventá-lo à nossa maneira.

Entretanto, que não nos deixemos levar pela esperança vazia, paixão triste, de acreditar que sejam fáceis os caminhos. A manta asfáltica que pavimenta o terreno das irregularidades nos desacostumou a andar por relevos escorregadios e as luzes fortes efetivamente viciam a retina. Antes de tudo, cabe-nos a tarefa de reaprender a enxergar em meio ao pleno movimento dos tombos do nosso corpo. E isso só se fará possível no exercício da “transformação cotidiana desta terra" - que tanto suporta o programado quanto a desprogramação, que tanto aterra identidades quanto germina a diferenciação - pelas multidões cujas existências se dão por fora das medidas e cujo "potencial de criação só pode ser a multiplicidade dos devires" (LAZZARATO, 2004, p. 150).

Virgínia Kastrup (2008), articulada com o lema da pesquisa-intervenção, nos fala sobre transformar para conhecer; e com Maurizio Lazzarato (2004) entendemos que é preciso 


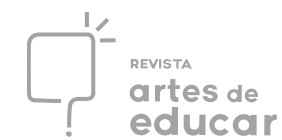

transformar para resistir, ali mesmo, nos interstícios borrados entre o que se diz do individual e o que se diz do coletivo, nas problematizações simultâneas das relações estratégicas e dos estados de dominação que nos possibilitam traçar linhas de fuga rumo à construção de outras técnicas de governo de si e dos outros. A aposta desta pesquisa foi - e ainda é -, pois, a de um pesquisar e um educar que se produz na imanência e iminência do viver, ou seja, a de acompanhar vidas de mulheres marisqueiras nos cenários a que somos convocadas, situandonos entre a academia e a vida, fazendo de uma e outra um desafio político, no lugar mesmo da experimentação, ou melhor, da experienciação: recusar o controle da experiência e sua submissão a uma causalidade técnica, sua captura em um conceito que impossibilite o que poderia ter de pluralidade, sua condução para um fim preestabelecido (LARROSA, 2011). De outro modo, negar as relações de apropriação, dando lugar às relações de escuta que, singulares e irrepetíveis, nos ponham dispostas a ouvir o que não sabemos, o que não queremos, o que não precisamos; que nos permitam, uma vez imersas na água, perder o pé e deixarmo-nos arrastar pelo que se vem ao encontro. E, assim, tal qual Edileuza em seu sonho, seguindo as pistas que se faziam bolinhas de gude ${ }^{\mathrm{xxii}}$, nos lançamos em um mergulho conduzido pelas idas e vindas de pistas móveis, como o movimento das marés.

\section{Como responder com vida a uma política de morte ${ }^{\text {xxiii }}$}

Dessas perguntas que fazem trincar algumas das cercas... Decerto, não é somente com questionamentos dessa natureza que somos sacudidas pelos caminhos que escolhemos seguir; nem essa trinca foi a primeira na aventura de imaginar outros mundos. Entre três autoras nordestinas, que insistem na academia, uma de nós é travesti. E viver no país que mais mata travestis e mulheres transexuais ao passo em que mais consome pornografia com esses corpos é ter que lidar, diariamente, com diferentes modalidades e intensidades dessa política de morte; diariamente inventar vida. Aos poucos, vão se fazendo aparentes os movimentos constritivos que nos conduzem ao longo do tubo digestivo do monstro que nos engoliu, mas não porque se tornou fácil lê-los. É justamente nas dificuldades de encará-los e reconhecê-los onde residem as possibilidades de enfrentá-los. Portanto, é diante do horror desta realidade - deste presente eternizado por um projeto falho de futuro ao qual fomos e ainda somos submetidas - "que pode ter parecido uma mera utopia em toda a existência humana" que "nós, os inventores de fábulas, que acreditamos em qualquer coisa, nos sentimos inclinados a acreditar que ainda não é tarde demais para nos engajarmos na criação da utopia oposta ${ }^{\mathrm{xxiv}}$ ". 


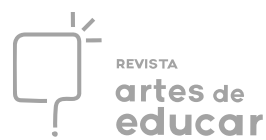

Reiteramos a pergunta feita ao final da "Carta das Águas Salgadas para as Mulheres de Povos e Comunidades Tradicionais ${ }^{\mathrm{xx}}$ ": quem mais se junta a essa luta? No final das contas, talvez, juntem-se a essa luta aquelas, aqueles, aquilo que recusa ouvir dizer que o fim é cinza, pois enxergam o mangue tanto um início em vida quanto enxergam em sua lama cinza um início em cor $^{\mathrm{xxvi}}$. Ou aqueles, aquelas e aquilo que fazem verter dos talhos nos seus corpos suados pela violência e chorados pela dor a água salgada que molha a lama do mangue e as mãos das marisqueiras em meio aos cantos de muitas tristezas. Aquelas, aqueles, os gestos, os movimentos que, como dito por Deleuze, seguem em flagrante delito de fabular.

Que possamos arriscar, então, a aumentar a temperatura entre os corpos em contato ao empurrar o céu ${ }^{\text {xxvii }}$ para fazer ruir as apertadas organizações do sólido da terra, não para desfazêla, mas, como já dissemos, para compô-la com o líquido e o gasoso de nossas invenções. O agora concentra todas as possibilidades que nos conduziram até aqui e que, certamente, podem nos tirar desse lugar. Clarice Lispector, certa vez, em um de seus romances, afirmou que criar é correr o risco de se ter a realidade. E nós, daqui, afirmamos que fabular, muito antes de delirar um futuro, é exercer a fazedura de um presente por trilhas feitas e desfeitas a todo instante. Assim como o poeta espanhol Antônio Machado nos contou: que façamos do caminhar as nossas possibilidades de caminho.

E se alguém alguma vez disse que a cabeça só pensa onde os pés pisam, que possamos insistir em fazer com que o coração ainda pulse lá onde os pés ainda possam estar envoltos de lama. Quem mais se junta a essa luta?

\section{REFERENCIAS}

BAUMAN, Z. Vidas desperdiçadas. Rio de Janeiro: Jorge Zahar Ed., 2005.

CLASTRES, P. Arqueologia da violência: pesquisas de antropologia política. São Paulo: Cosac e Naify, 2004.

CRUZ, E. S. do N. Caminhando por histórias da UFS: a produção da experiência de si pelas relações de poder-saber que se cruzam na SAES. Orientador: Prof. Dr. Marcelo de Almeida Ferreri. 2020. 128 f. Dissertação (Mestrado em Psicologia) - Programa de PósGraduação em Psicologia da Universidade Federal de Sergipe, São Cristóvão, Sergipe.

DELEUZE, G. Conversações. 1. ed. São Paulo: 34, 1992.

DUSSEL, E. 1492: O Encobrimento do Outro: a origem do "mito da modernidade". Petrópolis, Rio de Janeiro: Vozes, 1993. 


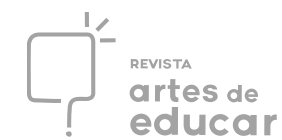

FREIRE, P. Pedagogia da autonomia: saberes necessários à prática educativa. São Paulo: Paz e Terra, 1996.

GONÇALVES, B. S. A Dupla Consciência Latino-Americana: contribuições para uma psicologia descolonizada. Revista Psicologia Política, São Paulo, v. 16, n. 37, p. 397-413, set./dez. 2016.

GUATTARI, F. As Três Ecologias. 11. ed. Campinas, São Paulo: Papirus, 2001.

HARAWAY, D. Saberes Localizados: a questão da ciência para o feminismo e o privilégio da perspectiva parcial. Cadernos Pagu, v.5. Campinas: Ed. Unicamp, p. 07-41, 1995.

JUNIOR, J. V. M. P. A expropriação psicológica do sujeito do sujeito no capitalismo tardio e a concepção neurocientífica do homem. Orientador: Prof. Dr. Ricardo Musse. 2018. 144 f. Dissertação (Mestrado em Sociologia) - Faculdade de Filosofia, Letras e Ciências Humanas da Universidade de São Paulo, São Paulo.

KASTRUP, V. A psicologia na rede e os novos intercessores. In: FONSECA, T. G.; FRANCISCO, D. J. (orgs.). Formas de ser e habitar a contemporaneidade. Porto Alegre: Editora da UFRGS, 2000. p. 13-22.

KASTRUP, V.; PASSOS, E. Cartografar é traçar um plano comum. Fractal: Revista de Psicologia, s.1.: v. 25, n. 2, p. 263-280, maio/ago. 2013.

KRENAK, A. Ideias para adiar o fim do mundo. São Paulo: Companhia das Letras, 2019.

LARROSA, J. Experiência e alteridade em educação. Revista Reflexão e Ação, Santa Cruz do Sul: v. 19, n. 2, p. 04-27, jul./dez. 2011.

LAZZARATO, M. Política da multiplicidade. In: LINS, D.; PELBART, P. P. (org.).

Nietzsche e Deleuze - Bárbaros, civilizados. São Paulo: Annablume, 2004. p. 147-157.

LOBO, L. F. Os infames da história: pobres, escravos e deficientes físicos no Brasil. Rio de Janeiro: Lamparina, 2008.

LOUREIRO. C. F. B. Sustentabilidade e Educação: um olhar da ecologia política. São Paulo: Cortez, 2012.

Educação Ambiental Transformadora. In: LAYRARGUES, P. P. (coord.). Identidades da Educação Ambiental Brasileira. Ministério do Meio Ambiente, Diretoria de Educação Ambiental. Brasília: Ministério do Meio Ambiente, 2004.

MBEMBE, A. Necropolítica. Arte \& Ensaios, São Paulo, n. 32, p. 123-151, 7 dez. 2016.

MOMBAÇA, J. Rumo a uma redistribuição desobediente de gênero e anticolonial da violência. In: Cadernos do grupo de pesquisa Oficina de Imaginação Política. Publicação comissionada pela 32ª Bienal de São Paulo. São Paulo: Incerteza Viva, 2016.

NANCY, J. L. Equivalência de catástrofes: após Fukushima. Lisboa: Nada, 2014. 


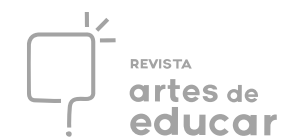

OLIVEIRA, A. R. S. et al. O processo formativo na educação ambiental crítica: a experiência do conselho gestor do PEAC. In: Anais da VII Jornada Internacional de Políticas Públicas. São Luís: Universidade Federal do Maranhão, 2015.

PASSOS, E; KASTRUP, V. Sobre a validação da pesquisa cartográfica: acesso à experiência, consistência e produção de efeitos. Fractal: Revista de Psicologia, s.l.: v. 25, n. 2, p. 391-414, maio/ago. 2013.

PELBART, P. P. O avesso do niilismo: cartografias do esgotamento. São Paulo: N-1 Edições, 2013. 345 p.

PRIGOGINE, I. As matemáticas do tempo. In: CARVALHO, E. de A.; ALMEIDA, M. da C. de (org.). Ciência, razão e paixão. Belém: EDUEPA, 2001. p. 74-78.

ROLNIK, S. À sombra da cidadania: alteridade, homem da ética e reinvenção da democracia. In: MAGALHÃES, M. C. R. (org.). Na sombra da cidade. São Paulo: Escuta, 1995. p. 141170.

ROSE, N. Administrando indivíduos empreendedores. In: FERREIRA, A. A. L. (trad.).

Inventando novos selfs: psicologia, poder e subjetividade. Petrópolis, Rio de Janeiro: Vozes, 2011. cap. 7, p. 209-233.

VASCONCELOS, M.; OLIVEIRA, S. Articulações salgadas entre o mito e a política: como enfrentar o inominável? In: LINS, M.; SANTOS, M. (Org). Entre o Mito e a Política.

Ebook. 2020.

\footnotetext{
${ }^{\text {i } U n i v e r s i d a d e ~ F e d e r a l ~ d e ~ S e r g i p e . ~ E-m a i l: ~ r o a r a t i a s @ g m a i l . c o m ; ~ A r a c a j u, ~ B r a s i l . ~ O R C I D: ~ h t t p: / / o r c i d . o r g / 0000-~}$ 0001-9666-5063.

ii Universidade Federal de Sergipe. E-mail: michelevasconcelos@hotmail.com; Aracaju, Sergipe. ORCID: http://orcid.org/0000-0002-9013-6352.

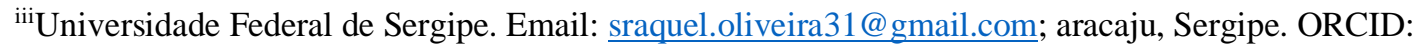
http://orcid.org/0000-0001-6611-9969.
}

\begin{abstract}
iv "Foram me chamar, eu estou aqui, o que é que há. Eu vim de lá, eu vim de lá, pequenininho. Mas eu vim de lá, pequenininho. Alguém me avisou pra pisar neste chão devagarinho" (“Alguém me avisou”, samba de dona Ivone Lara, no álbum Sorriso Negro de 1981).

` Para Donna Haraway (1995, p. 18), a barriga do monstro eram os Estados Unidos no final da década de 1980, assim como todas as "sociedades científicas e tecnológicas, pós-industriais, militarizadas, racistas e dominadas pelos homens", pautadas por uma produção de conhecimento descorporificada. Falar da barriga do monstro significava, portanto, se recusar a sair do campo da ciência enquanto possibilidade de construí-la de outra maneira; por dentro de suas próprias engrenagens.

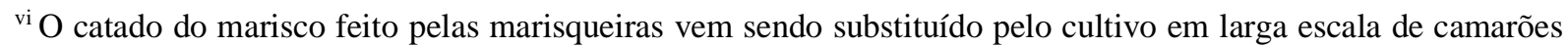
para exportação, um empreendimento conhecido por carcinicultura, que consiste no cultivo de camarão em tanques nos rios, com a utilização de agrotóxicos. Na lavagem dos tanques, a água com agrotóxico mistura-se à água do rio, causando a morte de peixes e mariscos, ademais, provocando intoxicação nas pessoas.

vii Menção a um trecho da música "Fogueira Doce”, composta por Mateus Aleluia e lançada em 2017 num álbum de mesmo nome.
\end{abstract}

Revista Interinstitucional Artes de Educar. Rio de Janeiro, V. 7, N. 1 - pág. 210-231 janeiroabril de 2021: "Pedagogias Vitais: Corpo, Desejo e Educação" DOI: 10.12957/riae.2021.53923 
viii Termo cunhado por Immanuel Wallerstein (1930-2019) em seu trabalho "O sistema-mundo moderno", publicado em quatro volumes, entre 1974 e 2011.

${ }^{\text {ix }}$ Numa entrevista concedida em 2014 ao Instituto Humanitas Unisinos, ao ser perguntado sobre a morte do colonialismo, o sociólogo argelino afirmou que "longe de estar morto, o colonialismo conhece, ao contrário, uma segunda juventude com a crise sistêmica do capitalismo".

x Trecho e título da música composta por Marcelo Yuka e lançada pela banda O Rappa, em álbum homônimo datado de 1994.

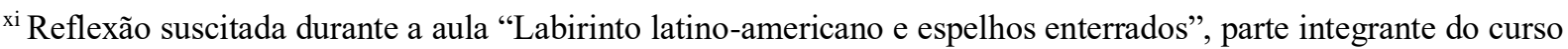
"Pensamento De(s)colonial e América Latina: memórias, afetos e futuros possíveis" ministrado pelo professor Bruno Simões Gonçalves, pós-doutor em Psicologia pela Universidade Federal do Rio de Janeiro.

xii Termo proposto a partir da década de 1970 pelos movimentos ambientalistas na tentativa de tipificar penalmente a destruição sistemática e deliberada de ecossistemas.

xiii Clastres (2004) nos ajuda a distinguir e, ao mesmo tempo, compreender as articulações entre esses termos. Em um texto publicado em 1974, ele lembra que, até bem pouco tempo, o termo etnocídio não existia. Para ele, se surgiu a necessidade de criar uma palavra é porque havia algo novo a pensar ou algo de antigo ainda não pensado. E foi justamente a realidade indígena da América do Sul que suscitou a formulação desse conceito. Não que o termo genocídio, esse fruto do "racismo que desenvolve livremente, como foi no caso da Alemanha nazista" (CLASTRES, 2004, p. 78), não seja adequado para se referir ao extermínio das populações indígenas latinoamericanas. Entretanto, se o genocídio remete à vontade de extermínio de uma minoria racial, etnocídio aponta para uma destruição sistemática dos modos de vida e pensamento de povos diferentes. Consideramos muito importante salientar uma característica que está no cerne da distinção entre os dois termos: o etnocídio admite a relatividade do mal que há na diferença, portanto, pode-se "melhorar" os outros, transformando-os até que se tornem, se possível, o mais idêntico ao modelo que lhes é imposto; realização máxima e salvadora da padronização unificadora dos mundos. Vale lembrar que o genocídio não sai de cena, está frequentemente articulado e no horizonte de todas as estratégias de resistência a essa pasteurização da diferença.

${ }^{\text {xiv }}$ A não ser que atualizemos a noção de acidental, tal qual Jean-Luc Nancy (2014) propõe ao pensar as catástrofes inseridas nos cálculos dos lucros dos investidores no contexto do capitalismo avançado, reconstruindo a própria noção de natural. Nesse sentido, e a partir de uma noção bastante cara de "técnica", para o filósofo não existem mais catástrofes naturais, apenas uma catástrofe civilizacional que se desdobra e se propaga por toda a parte.

${ }^{\mathrm{xv}}$ Título inspirado no texto de Bruno Latour (2020), intitulado "Imaginar gestos que barrem o retorno da produção pré-crise", que integra a coleção "Pandemia Crítica" da editora n-1. Para acessar: 〈https://n-1edicoes.org/textos$1>$.

xvi Para Bauman (2005, p. 12), “a produção de 'refugo humano', ou, mais propriamente, de seres humanos refugados é um produto inevitável" da chamada modernização das sociedades ocidentais; são aqueles que recusaram ou não tiveram permissão para permanecer dentro das fronteiras que delimitam o ideal de humanidade. xvii Lilia Lobo (2008) toma essa expressão foucaultiana como ferramenta para pensar, no contexto brasileiro, o que está presente em nossa história, mas que ao mesmo tempo não aparece. Essas existências são para ela: sem notoriedade, obscuras, como milhões de outras desapareceram e desaparecerão sem deixar rastro. Foram vidas detidas por uma instituição, aprisionadas pelas condições que lhes foram impostas, maldição das relações de poder. Segundo ela, sua lenda é invertida, turva, interrompida, perdida no fundo do baú das coisas inúteis.

xviii Menção à música "Retiros Espirituais", de autoria do cantor e compositor baiano Gilberto Gil, lançada em 1975 no álbum "Refazenda".

xix Menção à música "Retiros Espirituais", de autoria do cantor e compositor baiano Gilberto Gil, lançada em 1975 no álbum "Refazenda".

xx "O Brasil e a lógica do desastre", 11 de novembro de 2019.

xxi O químico Ilya Prigogine (1917 -2003) refere-se a essa frase de H. Bergson no momento final do capítulo "As matemáticas do tempo", em seu livro "Ciência, razão e paixão".

xxii Edileuza Cruz (2020, p. 37) nos convoca a "onirizar a política e politizar os sonhos", a trilhar com ela uma pesquisa-andança guiada pelas bolinhas de gude de seu sonho, que se faziam "indicadores dispersos do caminho" que ali se fazia; bolinhas essas que "pareciam marcas de uma época em que o viver, o brincar e o historiar andavam

Revista Interinstitucional Artes de Educar. Rio de Janeiro, V. 7, N. 1 - pág. 210-231 janeiroabril de 2021: "Pedagogias Vitais: Corpo, Desejo e Educação" DOI: 10.12957/riae.2021.53923 
juntos, sem muitas diferenciações" (idem, 2020, p. 14). Fazendo nossas as suas palavras: que as águas inquietas dos mangues nos sejam as marcas de um viver, um mariscar e um pesquisar sem muitas distinções.

xxiii Pergunta feita pelo professor Leomir Hilário, do Departamento de Psicologia da Universidade Federal de Sergipe, em uma de suas aulas da disciplina de Psicologia Social III lecionada no ano de 2019.

xxiv Trecho do discurso de Gabriel García Márquez no recebimento do Prêmio Nobel de Literatura, 1982.

${ }^{x x v}$ Carta lida na ocasião de abertura do Observatório Popular de Violências e pela Vida das Mulheres de Povos e Comunidades Tradicionais de Sergipe (VASCONCELOS; OLIVEIRA, 2020, p. 123-124).

xxvi Menção à música “Amor Cinza”, composta por Mateus Aleluia, do álbum “Cinco sentidos” (2010).

xxvii Ailton Krenak (2019, p. 13), sobre a importância de "viver a experiência da nossa própria circulação pelo mundo, não como uma metáfora, mas como fricção". 